\title{
Research on the Factors Affecting the Continuous Participation Behavior of Virtual Brand Community Customers
}

\author{
Tao $\mathrm{Li}^{1}$ Huili $\mathrm{YaO}^{2, *}$ \\ ${ }^{1,2}$ School of Economics and Management, Jiangsu University of Science and Technology, Zhenjiang Jiangsu 212003, \\ China \\ *Corresponding author. Email: $994093793 @ q q . c o m$
}

\begin{abstract}
Based on the information system expectation confirmation model, this paper constructs a structural equation model of the continuous participation behavior of customers in the virtual brand community, and explores the key factors affecting customer satisfaction and continuous participation behavior. Through the questionnaire survey of Xiaomi community customers, the model was analyzed and verified by SPSS and AMOS. Finally, the results show that expectation confirmation, perceived usefulness, and perceived interest indeed all have a positive impact on satisfaction. Satisfaction, emotional commitment, calculation commitment and habit have positive effects on continuous participation behaviour. Emotional commitment and calculation commitment have influence on satisfaction and play a part of a role of intermediary. The research results have implications for the management of virtual brand communities.
\end{abstract}

Keywords: continuous participation, structural equation, customer commitment

\section{INTRODUCTION}

The virtual brand community is an extremely important environment to sustain the relationship between customers and enterprises. Customer participation is only a small step in the success of the community. Continuous participation can generate great business value. In recent years, many scholars have proposed that continuous participation is a continuation of participation behavior, and more and more attention has been paid to the research of continuous customer participation, and the research area is also expanding. However, in the existing research, the research on the continuous participation of the virtual brand community has rarely involved the attitude conversion process from initial customer participation to continuous participation.

This article takes the Xiaomi community as the research scenario, and based on the information system expectation confirmation model (ECM-ISC), combined with the commitment theory, explores the leading factors and influencing effects of the continuous participation of customers. So, the practical significance of the research in this paper is to build a model of influencing factors for continuous customer participation, which has objective guidance for observing customer behaviors, and it is convenient for community managers to take effective methods to encourage continuous customer participation and promote community improvement and development.

\section{THEORETICAL AND HYPOTHESES}

\subsection{Related theoretical research}

\subsubsection{Information System Expectation Confirmation Model (ECM-ISC)}

Bhattacherjee created the Information System Expectation Confirmation Model (ECM-ISC), explaining the motivations of users' continued use and how the motivations affect the intention of continuous use [1]. In essence, the virtual brand community is an information exchange system. After customers accept this system, more interaction means more continuous participation. Therefore, the information system expects the confirmation model to be suitable for studying the continuous participation behavior of customers in the virtual brand community.

\subsubsection{Commitment Theory}

Customer commitment is gradually moving from a single dimension to multiple dimensions. Gustafsson divides commitments into computational commitments and emotional commitments [2]. Emotional commitment is a commitment generated by attachment. Interaction will cause the strengthening of customer's emotional commitment. Calculation commitments are mainly commitments generated after calculation of gains and losses [3]. After calculating costs and benefits, calculation commitments will be strengthened. In the context of this paper, due to the perceptual and rational characteristics of 
customers, it is reasonable to divide customer commitments into two dimensions when researching commitments, namely, "emotional commitments and calculation commitments."

\subsection{Research Hypotheses}

According to the expectation confirmation model of the information system, commitment theory and existing literature, this paper mainly selects 8 latent variables of expectation confirmation degree, perceived usefulness, perceived interest, satisfaction, emotional commitment, calculation commitment, and habit. A Factor Model is as shown in Figure 1.

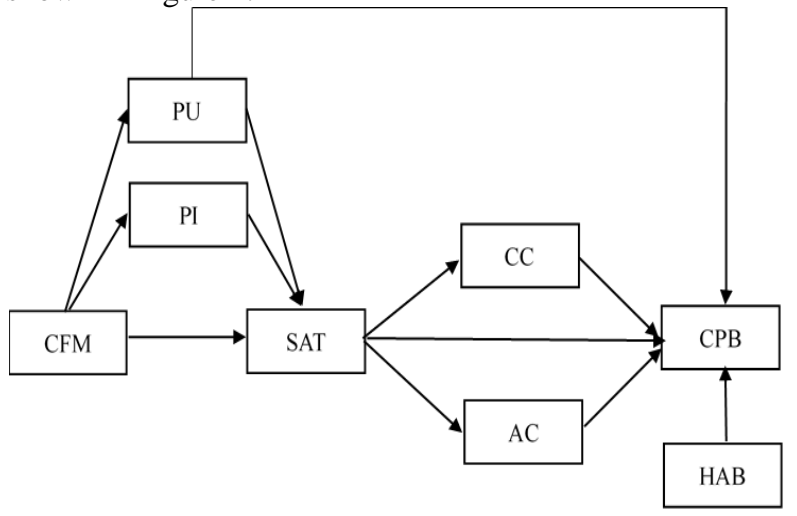

Figure 1 Model diagram

The relationship between expectation confirmation, perceived usefulness, satisfaction and continuous participation in the model still exists in the research. In the study of customer commitment, some scholars point out that customer commitment affects continuous participation and is the key "predictor" of continuous participation [4]. Although satisfaction and commitment are both the psychological state of customer participation, the difference is that commitment is a "psychological contract". When this "contract" is formed, the nature of behavior changes. As a result, increased levels of commitment will encourage customers to continue participating in the virtual brand community. Therefore, hypotheses are proposed:

$\mathrm{H} 1$ : Expected confirmation positively affects the perceived usefulness of customers.

$\mathrm{H} 2$ : Expectation confirmation positively affects customer satisfaction.

H3: Perceived usefulness positively affects customer satisfaction.

H4: Perceived usefulness positively influences customers' continuous participation behavior.

H5: Satisfaction directly affects customers' continuous participation behavior.

H6: Customer's emotional commitment positively affects customers' continuous participation behavior.

H7: Customer's calculation commitments positively affect customers' continuous participation behavior.

H8a: Satisfaction positively affects customer continuous participation behavior through the mediating effect of emotional commitment.

H8b: Satisfaction positively influences customers' continuous participation behavior through the mediating role of computing commitment.
In general, people are interested in the experience of products and services, but the experience is lower than expected and they will not be interesting. The perceived interest of customers is the pleasure and interesting psychological state in the customer experience. Only when the community content meets the customer's expectations can the customer's interest be stimulated. At the same time, the enjoyment of the fun will form a positive attitude, awaken emotional responses and sharing behaviors. And continue to participate. Therefore, hypotheses are proposed: H9: Expectation confirmation positively affects perceived interest.

H10: Perceived interest positively affects customer satisfaction.

Habits are sequential learning activities that automatically respond to specific cues and reach a given goal or state [5]. Long-term frequent community participants are more likely to form spontaneous unconscious behaviors, and customers often participate in virtual brand communities under the influence of habits. Because customers are accustomed to participating in the community, customers do not need complicated cognitive and rational decisions. Therefore, in addition to their willingness to participate, habit has a direct impact on continuous participation behaviors. Therefore, hypotheses are proposed:

H11: Habits positively influence ongoing participation.

\section{RESEARCH DESIGH AND EMPIRICAL ANALYSIS}

This research model includes a total of 8 potential variables, each of which includes 3-4 measured variables. All the measurement items are from existing research and mature domestic and foreign research scales, and are improved and adapted in accordance with the actual research problems to ensure that they meet the needs of specific research scenarios. All related items were measured by a 5-point Likert scale ( 1 means strongly disagree, 5 means strongly agree).

\subsection{Research Background}

This study uses the Xiaomi community as the research background and uses online questionnaires to survey customers in the Xiaomi community. After two months of data collection, 378 questionnaires were received, and a total of 318 questionnaires were excluded, with an effective rate of $84.1 \%$.

\subsection{Measurement Model Test}

Measurement model testing mainly includes reliability analysis and validity analysis. Reliability is an evaluation of the consistency, stability, and reliability of the measurement results. It is measured by the Cronbach ' $\alpha$ and the combined reliability (CR). If the general coefficient and $\mathrm{CR}$ are greater than 0.7, the reliability of the model Better [6]. We find that the CR value of each construct is greater than 0.8 , and the Cronbach' $\alpha$ is also greater than 0.8 . The data as a whole is 
more credible, indicating that the research model has better internal consistency. At the same time, the extracted average variance (AVE) is greater than the critical value of 0.5 , which has good convergence validity and meets the adaptation requirements [7]. The non-diagonal elements in Table 1 are the correlation coefficients of the dependent variables. According to the requirements of the discriminant validity test, when the diagonal elements are larger than the non-diagonal elements, the discriminant validity of the scale is better. The following table shows the correlation coefficients between the square root of AVE and the latent variables. The coefficients between the latent variables have significant correlation $(\mathrm{P}<0.001)$, and they are all smaller than the square root of the corresponding AVE. Correlation and a certain degree of discrimination between each other, indicating that the measurement model has good discrimination validity. As shown in Table 1 , as a whole, the indicators of the scale meet the requirements of reliability and validity tests.

Table 1 AVE square root and Correlation coefficients between latent variables

\begin{tabular}{|c|c|c|c|c|c|c|c|c|c|c|c|}
\hline Variables & $\begin{array}{l}\text { Cronba } \\
\operatorname{ch}^{\prime} \alpha\end{array}$ & AVE & CR & CFM & PU & PI & SAT & $\mathrm{CC}$ & $\mathrm{AC}$ & СРB & HAB \\
\hline CFM & 0.87 & 0.634 & 0.873 & 0.796 & & & & & & & \\
\hline PU & 0.837 & 0.632 & 0.837 & 0.413 & 0.795 & & & & & & \\
\hline PI & 0.843 & 0.643 & 0.844 & 0.325 & 0.457 & 0.802 & & & & & \\
\hline SAT & 0.822 & 0.608 & 0.823 & 0.427 & 0.496 & 0.426 & 0.780 & & & & \\
\hline $\mathrm{CC}$ & 0.842 & 0.575 & 0.844 & 0.269 & 0.365 & 0.188 & 0.341 & 0.758 & & & \\
\hline $\mathrm{AC}$ & 0.841 & 0.572 & 0.842 & 0.180 & 0.080 & 0.160 & 0.161 & 0.159 & 0.756 & & \\
\hline $\mathrm{CPB}$ & 0.883 & 0.656 & 0.884 & 0.235 & 0.268 & 0.173 & 0.360 & 0.358 & 0.398 & 0.810 & \\
\hline HAB & 0.894 & 0.739 & 0.895 & 0.222 & 0.204 & 0.091 & 0.239 & 0.223 & 0.310 & 0.405 & 0.860 \\
\hline
\end{tabular}

\subsection{Structural Model}

Structural model test is to test the degree of fit of the structural model to the data through the model fitting index. In this paper, it is appropriate to divide model fitting indicators into three categories, that is, absolute fitting

indicators, value-added fitting indicators, and simple fitting indicators. The breakdown of various types of indicators in this study is shown in Table 2. The fitting coefficients are all within the ideal value range.

\subsection{Structural Model}

Table 2 Fitting degree of structural equation model

\begin{tabular}{cccccccc}
\hline Index & \multicolumn{3}{c}{ Absolute fitting index } & Value-added fitting index & Simple fitting index \\
\hline $\begin{array}{c}\text { Specific } \\
\text { classification }\end{array}$ & $\chi 2 / \mathrm{df}$ & GFI & RMSEA & TLI & CFI & PGFI & PNFI \\
$\begin{array}{c}\text { Judgment } \\
\text { criteria }\end{array}$ & $<3$ & $>0.9$ & $<0.08$ & $>0.9$ & $>0.9$ & $>0.5$ & $>0.5$ \\
$\begin{array}{c}\text { Fitting } \\
\text { results }\end{array}$ & 1.465 & 0.901 & 0.038 & 0.960 & 0.964 & 0.750 & 0.801 \\
\hline
\end{tabular}

In this study, the path coefficients between the variables were calculated. As shown in the table, every hypothetical path was verified. When the CR value is greater than 1.96 , it corresponds to a significance level of $\mathrm{p}<0.05$; when the $\mathrm{CR}$ value is greater than 2.58 , it corresponds to a significance level of $\mathrm{p}<0.01$; when the $\mathrm{CR}$ value is greater than 3.29, it corresponds to a significance level of $p<0.001$. As can be seen from Table 3 , it is expected that the confirmation will positively influence perceived usefulness $(\beta=0.425, \mathrm{P}<0.001)$ and perceived interest $(\beta=0.342, \mathrm{P}$ 
$<0.01)$ have significant positive effects on continuous participation. Impact; Perceived usefulness had no significant effect on continuous participation $(\beta=0.052, \mathrm{P}>$ $0.05)$.

It can be seen that the assumptions in the model except the $\mathrm{H} 4$, that is, the "perceived usefulness positively affects the customer's continuous participation behavior" assumption is not supported, all other assumptions have passed the significance test. ment $(\beta=0.197, \quad \mathrm{P}<0.01)$ and emotional commitment $(\beta=0.278, \mathrm{P}<0.01)$ have obvious positive effects on continuous participation; habits $(\beta=0.257$, $\mathrm{P}$

Table 3 Path coefficient estimation

\begin{tabular}{cccccccc}
\hline & Path & & Non-standardized & Normalization & S.E. & C.R. & P \\
\hline PU & $<---$ & CFM & 0.483 & 0.425 & 0.075 & 6.423 & $* * *$ \\
PI & $<---$ & CFM & 0.388 & 0.342 & 0.074 & 5.241 & $* * *$ \\
SAT & $<---$ & PU & 0.265 & 0.323 & 0.058 & 4.608 & $* * *$ \\
SAT & $<---$ & PI & 0.190 & 0.230 & 0.053 & 3.549 & $* * *$ \\
SAT & $<---$ & CFM & 0.224 & 0.239 & 0.066 & 3.381 & $* * *$ \\
CC & $<---$ & SAT & 0.292 & 0.367 & 0.055 & 5.310 & $* * *$ \\
AC & $<---$ & SAT & 0.208 & 0.178 & 0.079 & 2.645 & 0.008 \\
CPB & $<---$ & CC & 0.238 & 0.197 & 0.078 & 3.033 & 0.002 \\
CPB & $<---$ & SAT & 0.172 & 0.179 & 0.073 & 2.349 & 0.019 \\
CPB & $<---$ & AC & 0.228 & 0.278 & 0.050 & 4.526 & $* * *$ \\
CPB & $<---$ & HAB & 0.235 & 0.257 & 0.053 & 4.455 & $* * *$ \\
CPB & $<---$ & PU & 0.041 & 0.052 & 0.054 & 0.760 & $\mathbf{0 . 4 4 7}$ \\
\hline
\end{tabular}

\subsection{Intermediate Effect Test}

This study used the Bootstrap program to test the significance of the mediation effect. First, use the repeated random sampling method to extract 2000 Bootstrap samples from the original data $(\mathrm{N}=318)$, and then fit the model based on these samples to generate and save 1000 estimates of the mediation effect to form an approximate sampling distribution. At the same time, calculate Mean path value of the mediation effect, and sort these effect values by numerical value, using the 2.5 th and 97.5 th percentiles to estimate the $95 \%$ confidence interval for the mediation effect. If the $95 \%$ confidence intervals for these path coefficients do not include 0 , it indicates that the mediation effect is significant.

From Table 4, the 95\% confidence intervals of the paths "Satisfaction-> Calculation commitment-> Continuous participation" and "Satisfaction-> Emotional commitment-> Continuous participation" do not include 0 , and the significance test passes. It shows that calculation commitment and emotional commitment have significant mediating effects between satisfaction and continuous participation.

Table 4 Bootstrap analysis of the significance test of the mediating effect of emotional commitment and calculated commitment

\begin{tabular}{|c|c|c|c|c|c|}
\hline \multirow{2}{*}{ Path } & \multirow{2}{*}{$\begin{array}{l}\text { Standardized indirect } \\
\text { effect estimates }\end{array}$} & \multirow{2}{*}{$\begin{array}{c}\text { Mean } \\
\text { indirect } \\
\text { effect }\end{array}$} & \multicolumn{2}{|c|}{$95 \%$ confidence interval } & \multirow[b]{2}{*}{$\mathrm{P}$} \\
\hline & & & Lower limit & Upper limit & \\
\hline SAT-->CC-->CPB & $0.37 * 0.20=0.074$ & 0.069 & 0.015 & 0.152 & 0.009 \\
\hline SAT-->AC-->CPB & $0.18 * 0.28=0.050$ & 0.048 & 0.008 & 0.110 & 0.016 \\
\hline
\end{tabular}

\section{CONCLUSION AND DISCUSSION}

\subsection{Intermediate Effect Test}

The continuous customer participation is very important for healthy and stable growth of the brand community. This paper validates the applicability of the information system expectation confirmation model in the continuous participation behavior of virtual brand customers. According to the analysis results, 11 of the hypotheses passed the significance test, which supports the null hypothesis; one was not significant, that is, finally the perceived hypothesis that "the perceived usefulness 
Equation Modeling[J]. International Statistical Review, 2013, 83(2):325-326.

[7] Bagozzi R P. Evaluating Structural Equation Models with Unobservable Variables and Measurement Error: A Comment[J]. Journal of Marketing Research, 1981, 18(3):375-381.

\subsection{Management Inspiration}

The research conclusions of this paper have certain reference significance for the development of virtual brands. First, community managers should be aware of the lack of a deeper link between satisfaction and continued participation. The community manager should consider the customer's emotions and rational judgments at the same time, and establish the emotional connection while taking into account the customer's interests. Because direct benefits are often an effective way to retain customers. Second, accurately find the corresponding customer demands. Customer demands are constantly changing. Community managers can analyze customer needs and feedback in stages, analyze customer preferences for participating in the community, and continuously optimize the community interface and functional services, so that it becomes a habit for customers.

\section{REFERENCES}

[1] Anol Bhattacherjee. Understanding information systems continuance: an expectation-confirmation model[J]. MIS Quarterly, 2001, 25(3):351-370.

[2] Gustafsson A, Johnson M D, Roos I. The Effects of Customer Satisfaction, Relationship Commitment Dimensions, and Triggers on Customer Retention[J]. Journal of Marketing, 2005, 69(4):210-218.

[3] Bateman P J, Gray P H, Butler B S. Research Note-The Impact of Community Commitment on Participation in Online Communities[M]. INFORMS, 2011.

[4] Z. Zhou, Y. Fang, D.R. Vogel, X.L. Jin, X. Zhang, Attracted to or locked in? Predicting continuance intention in social virtual world services J. Manag. Inf. Syst. 29 (1), 2012, pp. 273-305.

[5] Chiu C, MHsu M H, Lai H, et al. Re-examining the influence of trust on online repeat purchase intention: The moderating role of habit and its antecedents[J]. Decision Support Systems, 2012, 53(4):835-845.

[6] Hatcher L, O'Rourke N. A Step-By-Step Approach to Using SAS System for Factor Analysis and Structural 